\title{
Limitations of Fat-Free Mass for the Assessment of Muscle Mass in Obesity
}

\author{
Björn Jensen ${ }^{a} \quad$ Wiebke Braun $^{b} \quad$ Corinna Geisler ${ }^{b} \quad$ Markus Both $^{c}$ \\ Kristin Klückmann ${ }^{a}$ Manfred J. Müller ${ }^{b}$ Anja Bosy-Westphal ${ }^{b}$ \\ ${ }^{a}$ seca gmbh \& co. kg, Hamburg, Germany; ${ }^{b}$ Institut für Humanernährung und \\ Lebensmittelkunde, Christian-Albrechts-Universität Kiel, Kiel, Germany; ${ }^{c}$ Klinik für \\ Diagnostische Radiologie, Universitätsklinikum Schleswig-Holstein, Kiel, Germany
}

\section{Keywords}

Bioelectrical impedance analysis · Fat-free mass · Four-compartment model · Sarcopenia ·

Skeletal muscle mass

\begin{abstract}
Background: A high amount of adipose tissue limits the accuracy of methods for body composition analysis in obesity. Objectives: The aim was to quantify and explain differences in fat-free mass (FFM) (as an index of skeletal muscle mass, SMM) measured with bioelectrical impedance analysis (BIA), dual energy $X$-ray absorptiometry (DXA), air displacement plethysmography (ADP), and deuterium dilution in comparison to multicompartment models, and to improve the results of BIA for obese subjects. Methods: In 175 healthy subjects ( 87 men and 88 women, BMI $20-43.3 \mathrm{~kg} / \mathrm{m}^{2}, 18-65$ years), FFM measured by these methods was compared with results from a 3- (3C) and a 4-compartment (4C) model. $\mathrm{FFM}_{4 \mathrm{C}}$ was compared with SMM measured by magnetic resonance imaging. Results: BIA and DXA overestimated and ADP underestimated FFM in comparison to $3 C$ and $4 C$ models with increasing BMI (all $p<0.001$ ). Differences were largest for DXA. In obesity, BIA results were improved: value corrected $_{=}$ value $_{\text {uncorrected }}-a\left(\mathrm{BMI}-30 \mathrm{~kg} / \mathrm{m}^{2}\right), a=0.256$ for FFM and $a=0.298$ for SMM. SMM accounts for $45 \%$ of FFM in women and $49 \%$ in men. Conclusions: In obesity, the use of FFM is limited by a systematic error of reference methods. In addition, SMM accounts for about $50 \%$ of FFM only. Corrected measurement of SMM by BIA can overcome these drawbacks.
\end{abstract}


Jensen et al.: Limitations of FFM for the Assessment of Muscle Mass in Obesity

\section{Introduction}

Measurement of body composition is especially important in obesity because a low muscle mass can be obscured by a high amount of adipose tissue. "Hidden cachexia" and "hidden sarcopenia" have been increasingly recognized as high-risk phenotypes associated with adverse health outcomes like asthma and high cholesterol levels [1], and they also limit therapeutic success and affect patient prognosis [2,3]. Identification of muscle loss at an early stage as well as monitoring of body composition during therapeutic interventions are therefore critical and require repeat measurements with noninvasive and clinically accessible technology. In this regard, bioelectrical impedance analysis (BIA) has gained importance because of technological advances and improved validation of outcome measures [4]. This is supported by the growing number of publications that provide impedance-based reference data for fat-free mass (FFM) or skeletal muscle mass (SMM) [5-10].

The validity of BIA for body composition analysis in obesity is challenged by the assumption of a constant hydration of FFM that is violated by the higher hydration of FFM in adipose tissue and the higher ratio of extracellular (ECW) to intracellular water (ICW) in the adipose tissue part of connective tissue [11]. This drawback however applies to all body composition techniques that are based on a 2-compartment model that divides the body into fat and fat-free mass, and can only be ruled out by a 3-compartment (3C) model that avoids the assumption of a constant hydration by measuring the water content of FFM [12]. Additional limitations come from the assumption of a constant mineral content of FFM because a higher percentage of fat mass (FM) was associated with a lower bone mineral density and could thus decrease the mineral content of FFM [13]. A 4-compartment (4C) model independently measures the water and mineral content of FFM, and thus provides the most accurate tool for FM and FFM measurements in obesity [14]. A 4C model that requires the combination of densitometry by air displacement plethysmography (ADP) or underwater weighing, deuterium $\left(\mathrm{D}_{2} \mathrm{O}\right)$ dilution for measurement of total body water (TBW), and dual energy X-ray absorptiometry (DXA) for measurement of bone mineral content (BMC) is however cumbersome and not suitable for clinical practice. Therefore, the aim of the present study was (i) to quantify the impact of adiposity on the systematic error of BIA and other 2-compartment methods for the assessment of FFM by comparison versus a $3 \mathrm{C}$ and $4 \mathrm{C}$ model and (ii) to mathematically correct BIA equations for the systematic error with increasing adiposity. To evaluate the necessity of the additional DXA measurement required by the $4 \mathrm{C}$ model, we evaluated both, the $3 \mathrm{C}$ and the $4 \mathrm{C}$ model, as a reference.

Finally, the increase in connective tissue (i.e., adipose tissue) with obesity impairs the "metabolic quality" of FFM [4]. As a secondary aim of the study, the relationship between FFM and SMM was analyzed in order to evaluate the use of FFM as a proxy for SMM in obesity.

\section{Subjects and Methods}

In a first phase of this study, 153 Caucasian men and women with a BMI $<35 \mathrm{~kg} / \mathrm{m}^{2}$ were recruited from the area of Kiel, Germany, and FFM and SMM prediction equations for the seca medical body composition analyzer (mBCA) devices were developed [4, 15]. A seca mBCA 515 device (seca gmbh \& co. kg., Hamburg, Germany) was used for BIA measurements, and a 4C model based on $\mathrm{D}_{2} \mathrm{O}$ dilution, DXA, and ADP was used as reference for FFM, whereas whole-body magnetic resonance imaging (MRI) and sodium bromide $(\mathrm{NaBr})$ dilution were used as references for SMM and ECW, respectively. Details of the study protocol were described previously $[4,15]$. In a second phase, 35 obese Caucasian men and women with a BMI $\geq 30 \mathrm{~kg} / \mathrm{m}^{2}$ were examined using the same study protocol. Ten subjects of the first phase 
and 3 of the second phase had to be excluded from the study due to missing or implausible reference measurements. The results of the remaining 175 men and women aged 18-65 years were analyzed.

The subjects were asked to fast overnight and come to the study center between 07:00 and 07:30 in the morning. Whole-body MRI measurements took place at a separate appointment not more than 4 days apart. Subjects were excluded from the study if they fulfilled one of the following criteria: acute and/or chronic diseases (e.g., hypertension, renal and cardiac insufficiency), regular intake of medications (except for contraceptives), amputation of limbs, electrical implants as cardiac pacemaker, metallic implants (except for tooth implants), pregnancy or breastfeeding period, current alcohol abuse, and extensive tattoos at the arms or legs. Edema of the ankles were excluded by inspection and manual compression if appropriate.

\section{Anthropometrics}

Body height and weight were obtained on a measuring station (seca 285) with an accuracy of $\pm 50 \mathrm{~g}$ up to $100 \mathrm{~kg}$ and $\pm 75 \mathrm{~g}$ up to $150 \mathrm{~kg}$ for the scale and $\pm 2 \mathrm{~mm}$ for the stadiometer. BMI was classified as normal weight (BMI $\geq 18.5,<25 \mathrm{~kg} / \mathrm{m}^{2}$ ), overweight (BMI $\geq 25,<30 \mathrm{~kg} / \mathrm{m}^{2}$ ) and obesity (BMI $\geq 30 \mathrm{~kg} / \mathrm{m}^{2}$ ) with obesity class I (BMI $\geq 30,<35 \mathrm{~kg} / \mathrm{m}^{2}$ ), obesity class II $\left(\right.$ BMI $\left.\geq 35,<40 \mathrm{~kg} / \mathrm{m}^{2}\right)$, and obesity class III (BMI $\geq 40 \mathrm{~kg} / \mathrm{m}^{2}$ ).

\section{Bioelectrical Impedance Analysis}

The seca mBCA 515 device consists of a platform with an integrated scale and a handrail system. Each side of the ascending handrail carries 6 electrodes, of which 2 were chosen depending on the person's height. To get the right choice of grip position, the subject has to stand upright with outstretched arms. Another 2 pairs of electrodes contact the feet. This 8 -electrode technique enables segmental impedance measurements. Details of the device were previously described [15]. The accuracy for measurements of the right and left body side at frequencies of 5 and $50 \mathrm{kHz}$ is $5 \Omega$ for the impedance and $0.5^{\circ}$ for the phase angle. Prediction equations use BIA values obtained at 5 and $50 \mathrm{kHz}$ [15].

Participants were asked not to exercise within $12 \mathrm{~h}$ and drink alcohol within $24 \mathrm{~h}$ before the impedance measurement. The duration of each BIA measurement was $75 \mathrm{~s}$.

\section{Reference Methods}

FM was calculated using a $3 \mathrm{C}$ model and a $4 \mathrm{C}$ model that include body volume (by ADP), TBW (by $\mathrm{D}_{2} \mathrm{O}$ dilution), BMC (by DXA), and weight using the following equations [14]:

$$
\begin{aligned}
& F M_{3 C}(\mathrm{~kg})=2.220 \times \text { body volume }(L)-0.764 \times T B W(L)-1.465 \times \text { weight }(\mathrm{kg}) \\
& F M_{4 C}(\mathrm{~kg})=2.7474 \times \text { body volume }(L)-0.7100 \times T B W(L)+1.4599 \times B M C(\mathrm{~kg})-2.0503 \text { weight }(\mathrm{kg}) .
\end{aligned}
$$

$\mathrm{FFM}_{3 \mathrm{C}}$ and $\mathrm{FFM}_{4 \mathrm{C}}$ were calculated as the difference between body weight and FM.

Body volume was measured with ADP using the BOD POD ${ }^{\mathrm{TM}}$ device (Cosmed, Italy). FM $\mathrm{ADP}_{\mathrm{AD}}$ was calculated from body density using Siri's [16] equation, and $\mathrm{FFM}_{\mathrm{ADP}}$ was calculated as the difference to body weight. A whole-body DXA scan was performed to measure BMC, FFM $_{\text {DXA, }}$, and lean soft tissue using a Hologic Discovery A densitometer and the whole-body software 12.6.1:3 (Hologic, Inc., Bedford, MA, USA). $\mathrm{D}_{2} \mathrm{O}$ dilution was used to measure TBW and $\mathrm{NaBr}$ dilution to assess ECW. $\mathrm{FFM}_{\mathrm{D}_{2} \mathrm{O}}$ was calculated by $F F M_{D_{2} O}(\mathrm{~kg})=T B W(L) / 0.732$. ICW was calculated as the difference between TBW and ECW. Details of these reference methods were described previously [15].

Total SMM (excluding head and neck) and visceral adipose tissue were measured by MRI using a Magnetom Avanto 1.5-T scanner (Siemens Medical Systems, Erlangen, Germany). Details were described previously [4]. 
Jensen et al.: Limitations of FFM for the Assessment of Muscle Mass in Obesity

Table 1. Characteristics of the study population

\begin{tabular}{lccc}
\hline & $\begin{array}{l}\text { Women } \\
(n=88)\end{array}$ & $\begin{array}{l}\text { Men } \\
(n=87)\end{array}$ & $\begin{array}{l}\text { All } \\
(n=175)\end{array}$ \\
\hline Age, years & $38.5 \pm 13.0$ & $38.6 \pm 11.6$ & $38.5 \pm 12.3$ \\
Weight, kg & $75.8 \pm 20.9$ & $88.8 \pm 16.7^{* * *}$ & $82.3 \pm 20.0$ \\
Height, cm & $168.4 \pm 6.6$ & $179.8 \pm 5.8^{* * *}$ & $174.1 \pm 8.4$ \\
$\mathrm{BMI}, \mathrm{kg} / \mathrm{m}^{2}$ & $26.6 \pm 6.5$ & $27.5 \pm 5.2$ & $27.0 \pm 5.9$ \\
$\mathrm{FMI}_{4 \mathrm{C}}, \mathrm{kg} / \mathrm{m}^{2}$ & $9.8 \pm 4.9$ & $7.1 \pm 4.1^{* * *}$ & $8.4 \pm 4.7$ \\
$\mathrm{FFM}_{4 \mathrm{C}}, \mathrm{kg}$ & $47.8 \pm 7.3$ & $66.0 \pm 7.2^{* * *}$ & $56.9 \pm 11.7$ \\
$\mathrm{SMM}_{\text {MRI }}, \mathrm{kg}$ & $21.7 \pm 3.8$ & $32.5 \pm 4.0^{* * *}$ & $27.1 \pm 6.7$ \\
\hline
\end{tabular}

FMI, fat mass index; FFM, fat-free mass; SMM, skeletal muscle mass; 4C, 4-compartment model; MRI, magnetic resonance imaging. ${ }^{* * *} p<$ 0.001 vs. women $(t$ test).

\section{Statistics}

Data analyses were performed with R software, version 3.0.1 (R Foundation for Statistical Computing, Vienna, Austria). Descriptive statistics and errors are presented as means \pm SD. Differences between women and men as well as significant errors were analyzed by $t$ test. The FM index (FMI) was calculated using the following formula: $F M I=F M /$ height $^{2}$. Significance of the Pearson correlation coefficients is based on Fisher's $\dot{z}$-transformation. For correction equations, a linear regression was calculated using the uncorrected value from subjects with BMI $\geq 30 \mathrm{~kg} / \mathrm{m}^{2}$. BMI $-30 \mathrm{~kg} / \mathrm{m}^{2}$ was used as independent variable, and the intercept was fixed to zero at $\mathrm{BMI}=30 \mathrm{~kg} / \mathrm{m}^{2}$ to enforce continuity between uncorrected and corrected values at the threshold of BMI $=30 \mathrm{~kg} / \mathrm{m}^{2}$. Regressions were calculated for FFM, SMM (total and segmental), TBW, ECW, and visceral adipose tissue. Significance of coefficients was assessed by $t$ test, and equations were corrected for BMI $\geq 30 \mathrm{~kg} / \mathrm{m}^{2}$ using these coefficients. The pure error was calculated as:

$$
\text { Pure error }=\sqrt{\frac{\sum(\text { predicted value }- \text { reference value })^{2}}{\text { number of observations }}} .
$$

A $p$ value $<0.05$ was considered significant, values $<0.01$ and $<0.001$ are indicated.

\section{Results}

Characteristics of the study population stratified by gender are given in Table 1. Men were heavier and taller than women and also had higher amounts of SMM and FFM, whereas FMI was higher in women. The BMI ranged from 20 to $43.3 \mathrm{~kg} / \mathrm{m}^{2}$, and the prevalence of normal weight, overweight, and obesity class I-III was $49,24,13,10$, and $4 \%$, respectively.

Table 2 shows the error of FFM for normal-weight, overweight, and obese subjects measured using BIA, DXA, ADP, or $\mathrm{D}_{2} \mathrm{O}$ dilution, and the $3 \mathrm{C}$ and the $4 \mathrm{C}$ model as a reference. BIA overestimated FFM in obese subjects for both models (3C and 4C). DXA overestimated FFM in all BMI groups and for both models; the systematic error increased with BMI (Tables 2, 3) and was largest in obese subjects. By contrast, ADP underestimates FFM in all BMI groups and for both models with the highest negative systematic error in obese subjects. No significant systematic error was found for $\mathrm{D}_{2} \mathrm{O}$ dilution. The highest systematic error was found for both models when FFM was measured with DXA in obese subjects. Significant differences between the $3 \mathrm{C}$ and the $4 \mathrm{C}$ model were only found in normal-weight subjects. 
Jensen et al.: Limitations of FFM for the Assessment of Muscle Mass in Obesity

Table 2. Error of fat-free mass (FFM) measured by bioelectrical impedance analysis (BIA), dual-energy X-ray absorption (DXA), air displacement plethysmography (ADP), and deuterium (D20) dilution in comparison with a 3-compartment (3C) and a 4-compartment (4C) model, stratified by normal weight, overweight, and obesity

\begin{tabular}{lccc}
\hline & $\begin{array}{l}\text { Normal weight } \\
(n=86)\end{array}$ & $\begin{array}{l}\text { Overweight } \\
(n=42)\end{array}$ & $\begin{array}{l}\text { Obesity } \\
(n=47)\end{array}$ \\
\hline $\mathrm{FFM}_{\mathrm{BIA}}-\mathrm{FFM}_{3 \mathrm{C}}, \mathrm{kg}$ & $-0.25 \pm 1.83$ & $-0.26 \pm 1.92$ & $1.39 \pm 2.41^{* * *}$ \\
$\mathrm{FFM}_{\mathrm{DXA}}-\mathrm{FFM}_{3 \mathrm{C}}, \mathrm{kg}$ & $1.09 \pm 1.34^{* * *}$ & $2.21 \pm 1.95^{* * *}$ & $5.25 \pm 2.10^{* * *}$ \\
$\mathrm{FFM}_{\mathrm{ADP}}-\mathrm{FFM}_{3 \mathrm{C}}, \mathrm{kg}$ & $-0.90 \pm 1.17^{* * *}$ & $-1.07 \pm 1.38^{* * *}$ & $-1.53 \pm 1.33^{* * *}$ \\
$\mathrm{FFM}_{\mathrm{D} 2 \mathrm{O}}-\mathrm{FFM}_{3 \mathrm{C}}, \mathrm{kg}$ & $-0.11 \pm 0.97$ & $-0.14 \pm 1.15$ & $0.26 \pm 1.04$ \\
$\mathrm{FFM}_{\mathrm{BIA}}-\mathrm{FFM}_{4 \mathrm{C}}, \mathrm{kg}$ & $-0.02 \pm 1.83$ & $-0.25 \pm 1.82$ & $1.34 \pm 2.40^{* * *}$ \\
$\mathrm{FFM}_{\mathrm{DXA}}-\mathrm{FFM}_{4 \mathrm{C}}, \mathrm{kg}$ & $1.32 \pm 1.33^{* * *}$ & $2.22 \pm 1.97^{* * *}$ & $5.19 \pm 2.05^{* * *}$ \\
$\mathrm{FFM}_{\mathrm{ADP}}-\mathrm{FFM}_{4 \mathrm{C}}, \mathrm{kg}$ & $-0.67 \pm 1.10^{* * *}$ & $-1.06 \pm 1.38^{* * *}$ & $-1.58 \pm 1.48^{* * *}$ \\
$\mathrm{FFM}_{\mathrm{D} 20}-\mathrm{FFM}_{4 \mathrm{C}}, \mathrm{kg}$ & $0.12 \pm 1.15$ & $-0.13 \pm 1.28$ & $0.20 \pm 1.03$ \\
$\mathrm{FFM}_{3 \mathrm{C}}-\mathrm{FFM}_{4 \mathrm{C}}, \mathrm{kg}$ & $0.23 \pm 0.33^{* * *}$ & $0.01 \pm 0.37$ & $-0.06 \pm 0.37$ \\
\hline
\end{tabular}

*** $p<0.001$ : error significantly different from zero by $t$ test.

Table 3. Correlations between the error of fat-free mass (FFM) assessed by different methods and potential determinants

\begin{tabular}{lcccl}
\hline & $\mathrm{FFM}_{\mathrm{BIA}}-\mathrm{FFM}_{4 \mathrm{C}}$ & $\mathrm{FFM}_{\mathrm{DXA}}-\mathrm{FFM}_{4 \mathrm{C}}$ & $\mathrm{FFM}_{\mathrm{ADP}}-\mathrm{FFM}_{4 \mathrm{C}}$ & $\mathrm{FFM}_{\mathrm{D} 20}-\mathrm{FFM}_{4 \mathrm{C}}$ \\
\hline $\mathrm{BMI}$ & $0.36^{* * *}$ & $0.73^{* * *}$ & $-0.31^{* * *}$ & 0.03 \\
$\mathrm{FMI}_{4 \mathrm{C}}$ & $0.46^{* * *}$ & $0.77^{* * *}$ & $-0.23^{* *}$ & $0.18^{*}$ \\
$\mathrm{BMC}_{\mathrm{DXA}} / \mathrm{FFM}_{4 \mathrm{C}}$ & $-0.16^{*}$ & $-0.29^{* * *}$ & $0.60^{* * *}$ & 0.06 \\
$\mathrm{TBW}_{\mathrm{D} 2 \mathrm{O}} / \mathrm{FFM}_{4 \mathrm{C}}$ & $0.20^{* *}$ & $0.19^{*}$ & $-0.70^{* * *}$ & n.c. \\
$\mathrm{ECW}_{\mathrm{NaBr}} / \mathrm{ICW}_{\mathrm{D} 2 \mathrm{O}, \mathrm{NaBr}}$ & $0.21^{* *}$ & $0.28^{* * *}$ & $0.23^{* *}$ & 0.01 \\
\hline
\end{tabular}

BIA, bioelectrical impedance analysis; 4C, 4-compartment model; DXA, dual energy X-ray absorptiometry; $\mathrm{ADP}$, air displacement plethysmography; D20, deuterium dilution; FMI, fat mass index; BMC, bone mineral content; TBW, total body water; ECW, extracellular water; ICW, intracellular water; NaBr, sodium bromide dilution. ${ }^{*} p<0.05,{ }^{* *} p<0.01,{ }^{* * *} p<0.001$ : correlation coefficients significantly different from zero.

The error of all methods increased with increasing FMI (the negative error in case of ADP; Table 3). In addition, the error of $\mathrm{FFM}_{\mathrm{ADP}}, \mathrm{FFM}_{\mathrm{DXA}}$, and $\mathrm{FFM}_{\mathrm{BIA}}$ also correlated with water and mineral content of FFM as well as the ECW/ICW ratio.

Figure 1 explains how BIA results for FFM were corrected for obese subjects. Without correction, BIA overestimates FFM at high FMI, and 22\% of the variance of the difference between $\mathrm{FFM}_{\mathrm{BIA}}$ and $\mathrm{FFM}_{4 \mathrm{C}}$ are explained by FMI (Fig. 1A). Instead of FMI, BMI was used for correcting FFM because it is independent of impedance measurements and can be used as a proxy for adiposity. Figure 1B shows that a systematic overestimation of FFM $_{\text {BIA }}$ only occurs when BMI exceeds $30 \mathrm{~kg} / \mathrm{m}^{2}$. A linear regression including subjects with BMI $\geq 30 \mathrm{~kg} / \mathrm{m}^{2}$ was therefore used for the correction of FFM $_{\text {BIA }}$ in obese subjects. To enforce continuity, the correction is zero at $\mathrm{BMI}=30 \mathrm{~kg} / \mathrm{m}^{2}$ (Fig. 1B). FFM was corrected by the following formula:

$$
F F M_{B I A} \text {, corrected }=F F M_{B I A, \text { uncorrected }}-0.256 \times\left(B M I-30 \mathrm{~kg} / \mathrm{m}^{2}\right) \text {. }
$$

No correction was applied for subjects with a BMI $<30 \mathrm{~kg} / \mathrm{m}^{2}$. This correction reduces the overestimation of FFM by BIA in obese subjects from $1.34 \pm 2.40$ to $-0.06 \pm 2.15 \mathrm{~kg}$ (online 


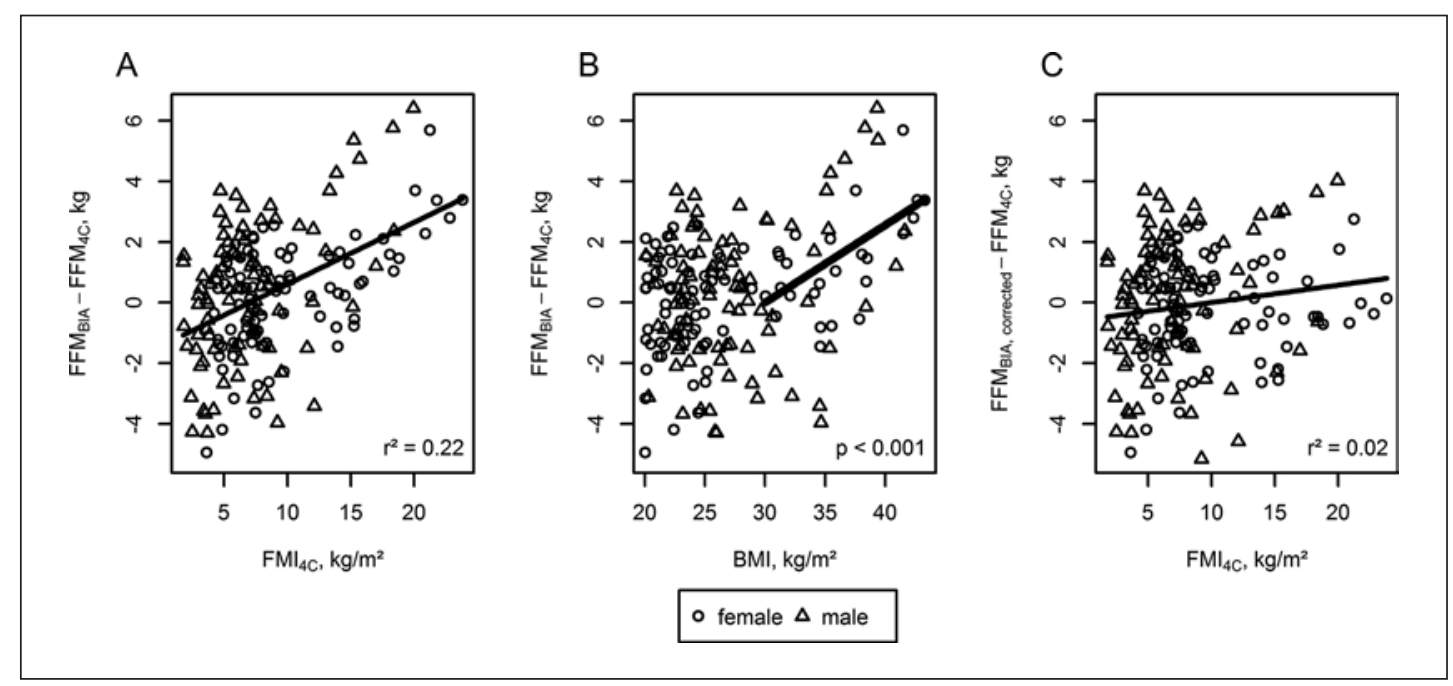

Fig. 1. Development of correction of fat-free mass (FFM) measured with bioelectrical impedance analysis (BIA). A Fat mass index (FMI) dependency of the error of uncorrected FFM in comparison to a 4-compartment (4C) model. B BMI dependency of the error for BMI $\geq 30 \mathrm{~kg} / \mathrm{m}^{2}$ which is used as correction, $\mathrm{FFM}_{\mathrm{BIA}}-\mathrm{FFM}_{4 \mathrm{C}}=0.256\left(\mathrm{BMI}-30 \mathrm{~kg} / \mathrm{m}^{2}\right)$. C Error of corrected FFM vs. FMI.

suppl.TableS1; for all online suppl. material, seewww.karger.com/doi/10.1159/000499607), and the variance in the difference between $\mathrm{FFM}_{\mathrm{BIA}}$ and $\mathrm{FFM}_{4 \mathrm{C}}$ explained by $\mathrm{FMI}$ is reduced from 22 to $2 \%$ (Fig. 1C). A similar correction can be applied to SMM, which reduces the error by BIA in obese subjects from $1.63 \pm 2.40$ to $0.01 \pm 2.11 \mathrm{~kg}$ :

$$
S M M_{B I A, \text { corrected }}=S M M_{B I A, \text { uncorrected }}-0.298 \times\left(B M I-30 \mathrm{~kg} / \mathrm{m}^{2}\right) .
$$

Further corrections can be applied to other BIA equations using the correction factors listed in online supplemental Table S1.

A linear relationship was found between FFM according to the 4C model and SMM measured by MRI (online suppl. Fig. 1). SMM accounts for $45 \%$ of FFM in women and for $49 \%$ of FFM in men. A significant correlation between the corresponding residuals and BMI was found in men $(r=0.22, p<0.05)$ but not in women. As a parameter describing the "quality" of FFM, the ECW/ICW ratio correlates with the residuals with $r=-0.26(p<0.05)$ in men and $r=$ $-0.54(p<0.001)$ in women. In contrast to BIA measurements of appendicular SMM (based on MRI as reference), SMM will be overestimated when appendicular lean soft tissue measured by DXA is used as a proxy (online suppl. Fig. S2).

Measuring the FFM with BIA using the FFM correction formula and calculating the SMM from FFM using the equations presented in online supplemental Figure 1 leads to a pure error for SMM of $1.50 \mathrm{~kg}$ for all subjects and $2.14 \mathrm{~kg}$ for obese subjects when compared to SMM measured by MRI, whereas measuring the SMM with BIA using the SMM correction formula leads to a pure error of $1.41 \mathrm{~kg}$ for all subjects and $2.09 \mathrm{~kg}$ for obese subjects.

\section{Discussion}

The primary aim of the present study was to quantify the impact of obesity on the systematic error of FFM measurements by BIA, DXA, ADP, and $\mathrm{D}_{2} \mathrm{O}$ dilution in comparison to a $3 \mathrm{C}$ and a $4 \mathrm{C}$ model and to correct BIA equations. We found that the error of all 2-compartment 
methods correlated with FMI (Table 3). BIA and DXA overestimated and ADP underestimated FFM with increasing obesity (Table 2). The overestimation of FFM in obesity by BIA equations was partly explained by a higher hydration of FFM (Table 3). In obesity, a higher hydration of FFM is due to an increased water fraction of FFM in adipose tissue [17]. For obesity, these effects were not adequately accounted for in the original BIA equations [4, 15], since inclusion criteria for the reference population used to generate the BIA algorithm were limited to BMI $<35 \mathrm{~kg} / \mathrm{m}^{2}$ [15]. On the other hand, overestimation of FFM by DXA can be explained by an underestimation of trunk FM by fan beam DXA devices [18]. Since mineral content of the TBW is largely responsible for X-ray attenuation and differentiation between FM and FFM [19, 20], a higher hydration of the FFM in adipose tissue also adds to the overestimation of FFM by DXA in obesity. However, the error of FFM measured by BIA or DXA was more dependent on BMI and FMI than on differences in hydration (Table 3). The accuracy of FFM measured by ADP depends on the assumption of a constant density of FFM [21]. A higher hydration or a lower $\mathrm{BMC}$ of the FFM in obesity therefore leads to a lower density and hence an underestimation of FFM, which is in accordance with the correlations given in Table 3.

The systematic error of FFM measured by $\mathrm{D}_{2} \mathrm{O}$ dilution was not significant in any BMI group, neither for the $3 \mathrm{C}$ nor for the $4 \mathrm{C}$ model. Therefore, $\mathrm{D}_{2} \mathrm{O}$ dilution is a valid method for measuring FFM in obesity, but is too time consuming for clinical practice. Differences between the $3 \mathrm{C}$ and the $4 \mathrm{C}$ model were only found in normal-weight subjects, suggesting that a $3 \mathrm{C}$ model might be sufficient in overweight and obese subjects if DXA measurements are not suitable.

The present study shows that the BIA equations can be improved for measurements in obese persons when a correction term for subjects with BMI $\geq 30 \mathrm{~kg} / \mathrm{m}^{2}$ is used (Fig. 1; online suppl. Table S1). This correction leaves results for nonobese subjects unchanged and avoids abrupt changes of results with increasing BMI. Correction factors were statistically significant $(p<0.001)$ for FFM, total SMM, SMM of the legs, TBW, and visceral adipose tissue, but not for SMM of the arms and ECW (online suppl. Table S1). In our study population (which was partly also used for the generation of BIA equations), the systematic error of the corrected BIA equation for FFM is lower than the systematic error of uncorrected DXA and ADP results. However, the standard deviation of the error in obesity is smaller in DXA and ADP (Table 2; online suppl. Table S1), which indicates a higher precision of those methods. As an alternative approach for the correction of BIA equations, we used a nonlinear (quadratic) correction over the complete BMI range. This approach resulted in a similar pure error compared to the linear correction beginning at $\mathrm{BMI}=30 \mathrm{~kg} / \mathrm{m}^{2}$.

A linear relationship was found between FFM according to the 4C model and SMM assessed by MRI (online suppl. Fig. S1). FFM can therefore be used for the prediction of SMM. However, SMM accounts for only $45-49 \%$ of FFM in women and men. This relationship also explains why appendicular muscle mass is overestimated when measured by DXA (online suppl. Fig. S2). While muscle tissue volume is measured with MRI, the results of DXA represent lean soft tissue mass which is FFM without bone. Therefore, lean soft tissue of the extremities as a proxy for SMM leads to an overestimation of muscularity [22]. Definitions of a low muscle mass that are based on different methods therefore differ between guidelines from the European Group on Sarcopenia in Older People and the International Consensus for Cancer Cachexia [23]. The prevalence of low muscle mass in patients with cancer may depend on the method of muscle measurement [24]. Using the seca mBCA 515 device, the prediction of SMM has advantages over the prediction of FFM because the pure error in comparison to MRI is smaller for the corrected SMM equation than for SMM calculated from corrected FFM (1.41 vs. $1.50 \mathrm{~kg}$ for all and 2.09 vs. $2.14 \mathrm{~kg}$ for obese subjects).

As a limitation to our study, participants were healthy, apart from being obese, and results may not be valid in subjects with diseases leading to disturbed hydration. Also, corrections 
were calculated for BIA equations implemented in the seca mBCA 515 device and cannot be applied to other BIA instruments. Furthermore, the $3 \mathrm{C}$ and $4 \mathrm{C}$ models as a reference were not independent because they included information derived from $\mathrm{ADP}, \mathrm{D}_{2} \mathrm{O}$ dilution, and DXA.

In conclusion, FFM measured by the reference methods DXA and ADP has a systematic error in obesity. These methods are therefore no appropriate standards for body composition in obesity. In clinical practice, the use of corrected BIA measurements for FFM or SMM can be a suitable alternative as long as BIA equations are validated versus a $4 \mathrm{C}$ or $3 \mathrm{C}$ model or MRI, like the equations implemented in the seca mBCA 515 device.

\section{Statement of Ethics}

This study was approved by the Medical Ethics Committee of the Christian Albrechts University Kiel, Germany, and has been performed in accordance with the ethical standards laid down in the 1964 Declaration of Helsinki and its later amendments. All subjects provided their fully informed and written consent before participation.

\section{Disclosure Statement}

Björn Jensen and Kristin Klückmann are employed by seca. Anja Bosy-Westphal serves and Manfred J. Müller served as consultant for seca. Wiebke Braun, Corinna Geisler, and Markus Both declare to have no conflict of interest.

\section{Funding Sources}

This work was supported by a grant from seca gmbh \& co. kg., Germany.

\section{Author Contributions}

B. Jensen and A. Bosy-Westphal designed research, analyzed data, and wrote the paper. W. Braun, C. Geisler, and M. Both conducted research. K. Klückmann designed and coordinated the research. M.J. Müller designed the research and contributed to the critical review and intellectual content of the manuscript. All authors read and approved the final manuscript.

\section{References}

1 Xiao J, Cain A, Purcell SA, Ormsbee MJ, Contreras RJ, Kim JS, et al. Sarcopenic obesity and health outcomes in patients seeking weight loss treatment. Clin Nutr ESPEN. 2018 Feb;23:79-83.

2 Fearon K, Arends J, Baracos V. Understanding the mechanisms and treatment options in cancer cachexia. Nat Rev Clin Oncol. 2013 Feb;10(2):90-9.

3 Prado CM, Lieffers JR, McCargar LJ, Reiman T, Sawyer MB, Martin L, et al. Prevalence and clinical implications of sarcopenic obesity in patients with solid tumours of the respiratory and gastrointestinal tracts: a population-based study. Lancet Oncol. 2008 Jul;9(7):629-35.

4 Bosy-Westphal A, Jensen B, Braun W, Pourhassan M, Gallagher D, Müller MJ. Quantification of whole-body and segmental skeletal muscle mass using phase-sensitive 8-electrode medical bioelectrical impedance devices. Eur J Clin Nutr. 2017 Sep;71(9):1061-7.

5 Schutz Y, Kyle UU, Pichard C. Fat-free mass index and fat mass index percentiles in Caucasians aged 18-98 y. Int J Obes Relat Metab Disord. 2002 Jul;26(7):953-60. 
6 Chumlea WC, Guo SS, Kuczmarski RJ, Flegal KM, Johnson CL, Heymsfield SB, et al. Body composition estimates from NHANES III bioelectrical impedance data. Int J Obes Relat Metab Disord. 2002 Dec;26(12):1596-609.

7 Dey DK, Bosaeus I, Lissner L, Steen B. Body composition estimated by bioelectrical impedance in the Swedish elderly. Development of population-based prediction equation and reference values of fat-free mass and body fat for 70- and 75-y olds. Eur J Clin Nutr. 2003 Aug;57(8):909-16.

8 Franssen FM, Rutten EP, Groenen MT, Vanfleteren LE, Wouters EF, Spruit MA. New reference values for body composition by bioelectrical impedance analysis in the general population: results from the UK Biobank. J Am Med Dir Assoc. 2014 Jun;15(6):448.e1-6.

9 Kudsk KA, Munoz-Del-Rio A, Busch RA, Kight CE, Schoeller DA. Stratification of Fat-Free Mass Index Percentiles for Body Composition Based on National Health and Nutrition Examination Survey III Bioelectric Impedance Data. JPEN J Parenter Enteral Nutr. 2017 Feb;41(2):249-57.

10 Chiplonkar S, Kajale N, Ekbote V, Mandlik R, Parthasarathy L, Borade A, et al. Reference Centile Curves for Body Fat Percentage, Fat-free Mass, Muscle Mass and Bone Mass Measured by Bioelectrical Impedance in Asian Indian Children and Adolescents. Indian Pediatr. 2017 Dec;54(12):1005-1011.

11 Wang Z, Deurenberg P, Heymsfield SB. Cellular-level body composition model. A new approach to studying fat-free mass hydration. Ann N Y Acad Sci. 2000 May;904(1):306-11.

12 Das SK. Body composition measurement in severe obesity. Curr Opin Clin Nutr Metab Care. 2005 Nov;8(6): 602-6.

13 Dolan E, Swinton PA, Sale C, Healy A, O'Reilly J. Influence of adipose tissue mass on bone mass in an overweight or obese population: systematic review and meta-analysis. Nutr Rev. 2017 Oct;75(10):858-70.

14 Fuller NJ, Jebb SA, Laskey MA, Coward WA, Elia M. Four-component model for the assessment of body composition in humans: comparison with alternative methods, and evaluation of the density and hydration of fat-free mass. Clin Sci (Lond). 1992 Jun;82(6):687-93.

15 Bosy-Westphal A, Schautz B, Later W, Kehayias JJ, Gallagher D, Müller MJ. What makes a BIA equation unique? Validity of eight-electrode multifrequency BIA to estimate body composition in a healthy adult population. Eur J Clin Nutr. 2013 Jan;67(S1 Suppl 1):S14-21.

16 Siri WE. Body composition from fluid spaces and density: analysis of methods. 1961. Nutrition. 1993 Sep-Oct; 9(5):480-91; discussion 480, 492.

17 Wang Z, Deurenberg P, Wang W, Pietrobelli A, Baumgartner RN, Heymsfield SB. Hydration of fat-free body mass: review and critique of a classic body-composition constant. Am J Clin Nutr. 1999 May;69(5):833-41.

18 Salamone LM, Fuerst T, Visser M, Kern M, Lang T, Dockrell M, et al. Measurement of fat mass using DEXA: a validation study in elderly adults. J Appl Physiol (1985). 2000 Jul;89(1):345-52.

19 Tylavsky F, Lohman T, Blunt BA, Schoeller DA, Fuerst T, Cauley JA, et al. QDR 4500A DXA overestimates fat-free mass compared with criterion methods.J Appl Physiol (1985). 2003 Mar;94(3):959-65.

20 Bosy-Westphal A, Müller MJ. Assessment of fat and lean mass by quantitative magnetic resonance: a future technology of body composition research? Curr Opin Clin Nutr Metab Care. 2015 Sep;18(5):446-51.

21 Ellis KJ. Human body composition: in vivo methods. Physiol Rev. 2000 Apr;80(2):649-80.

22 Cruz-Jentoft AJ, Baeyens JP, Bauer JM, Boirie Y, Cederholm T, Landi F, et al.; European Working Group on Sarcopenia in Older People. Sarcopenia: European consensus on definition and diagnosis: Report of the European Working Group on Sarcopenia in Older People. Age Ageing. 2010 Jul;39(4):412-23.

23 Gonzalez MC, Heymsfield SB. Bioelectrical impedance analysis for diagnosing sarcopenia and cachexia: what are we really estimating? J Cachexia Sarcopenia Muscle. 2017 Apr;8(2):187-9.

24 Blauwhoff-Buskermolen S, Langius JA, Becker A, Verheul HM, de van der Schueren MA. The influence of different muscle mass measurements on the diagnosis of cancer cachexia. J Cachexia Sarcopenia Muscle. 2017 Aug;8(4):615-22. 